\title{
Study on Influence Factors of Regional Flood Disaster Resilience Based on DEMATEL-ANP
}

\author{
Xianfu Cheng ${ }^{1,2}$, Honghu Sun ${ }^{1,2}$ \\ ${ }^{1}$ College of Territorial Resources and Tourism, Anhui Normal University, Wuhu 241003,China \\ ${ }^{2}$ Anhui Key Laboratory of Natural Disaster Precess and Prevention, Wuhu 241003,china
}

\begin{abstract}
The influence degree and causal relationship between the recognition factors are significant to the analysis of the key influencing factors of flood disaster resilience. Influencing factors of regional flood disaster resilience are selected from the five dimensions of nature, society, economy, technology and management. The importance and relevance of influencing factors of flood disaster resilience is analyzed using DEMATEL-ANP methods. The results showed that the government's financial support capacity, population density, regional economic strength are the most important for the regional flood disaster resilience. The level of regional flood disaster resilience can be improved directly by optimizing these factors.
\end{abstract}

Keywords: flood disaster; resilience; DEMATEL; ANP; factor identification

\section{基于DEMATEL-ANP的区域洪涝灾害恢复力影响 因素研究}

\author{
程先富 ${ }^{1,2}$, 孙鸿鹄 ${ }^{1,2}$ \\ 1 安徽师范大学国土资源与旅游学院, 芜湖 241003 , 中国 \\ 2 安徽自然灾害过程与防控研究省级实验室, 芜湖 241003 , 中国
}

\begin{abstract}
摘要: 识别因素间互相影响程度和因果关系, 对于分析洪涝灾害恢复力关键影响因素具有重要意义。从自然 维、社会维、经济维、科技维、管理维五个维度选取区域洪涝灾害恢复力的影响因素。应用 DEMATEL-ANP 方法分析洪涝灾害恢复力影响因素的重要性及关联性。结果表明: 政府的财政支持能力、人口密度、区域经 济实力对于区域洪涝灾害恢复力最重要, 通过优化这些因素可提高区域洪涝灾害恢复力的水平。
\end{abstract}

关键词: 洪港灾害; 恢复力; DEMATEL; ANP; 因素识别

\section{1. 引言}

恢复力已成为生态、环境灾害和气候变化等领域 研究的热点 ${ }^{[1]}$ 。随着灾害研究的不断深入, 灾害恢复 力在灾害管理中的重要性受到越来越多的关注 ${ }^{[2]}$ 。灾 害恢复力概念内涵也在不断地充实。联合国国际减 灾战略中将灾害恢复力定义为“系统、社区或社会抵 抗或改变的容量, 由系统能够自组织的能力、增加学 习的能力和适应的能力(包括从灾害中恢复的能力)

*基金项目：国家自然科学基金(42171516)
的容量决定”[3] Pelling 认为“自然灾害的恢复力是行 为者应对或适应灾害压力的能力, 是人们根据潜在的 灾害而采取的应对决策、规划性准备的程度, ${ }^{,[4]}$; 刘 婧和史培军等认为灾害恢复力是指系统没有被完全 破坏的条件下，只包括系统灾后调整、适应、恢复与 重建的能力 ${ }^{[2]}$; Riyanti 将其定义为国家或者社区利用 综合方式构建灾害弹性的能力 ${ }^{[5]}$ 。根据灾害恢复力的 内涵, 找出灾害恢复力的影响因子来构建综合评价指 标体系具有实际意义。 
Risk Analysis and Crisis Response in Big Data Era (RAC-16)

目前针对洪港灾害恢复力的影响因素、评价指标 体系 ${ }^{[6-9]}$ 等方面的研究多以社区微尺度为主 ${ }^{[10]}$, 指标 选择受人为影响大, 未能很好揭示影响因素在洪涝灾 害恢复力影响因素指标体系的地位, 以及因素之间的 关联性。为此, 本文将从自然、社会、经济、科术、 管理等五个维度构建区域洪涝灾害恢复力的影响因 素指标体系, 应用 DEMATEL 法与 ANP 法, 识别不 同因素的重要程度和关联程度, 为评价区域洪涝灾害 恢复力提供科学参考。

\section{2. 研究区概况与研究方法}

\section{1. 研究区概况}

安徽沿江地区位于安徽省南部, 处于 $116^{\circ} \sim$ $119^{\circ} \mathrm{E}, 30^{\circ} \sim 32^{\circ} \mathrm{N}$ 之间, 包括马鞍山、芜湖、铜陵、 池州、安庆和巢湖 6 个地级市及下辖的 20 个县, 总 面积 $39025 \mathrm{~km}^{2}$, 占全省总面积的 $27.95 \%$, 属于亚热 带湿润季风气候, 夏季高温多雨, 冬季寒冷干燥。年 平均气温 $16-17.3^{\circ} \mathrm{C}$, 常年无霜期达 $220-250$ 天, 年 平均降水量 770-1700mm 之间, 降水量多集中在 5-9 月, 地形以丘陵山地和平原为主。

\section{2. 研究方法}

DEMATEL( Decision Making Trial and Evaluation Laboratory, 决策实验室分析法) 法是一种利用矩阵 工具和图论对系统因素进行分析的方法。其核心思想 是根据系统中每个因素之间内在的逻辑关系, 构造出 直接影响矩阵, 进而计算出各个因素之间的影响和被 影响程度, 确定每个因素的原因度与中心度 ${ }^{[1]}$ 。基本 步骤如下:

(1) 构建指标体系, 设各影响因素为 $a_{1}, a_{2}, \ldots$, $a_{n}$ 。

（2）通过专家打分法确定不同因素间的直接影 响程度, 初始化直接影响矩阵。设 $n$ 阶矩阵 $X=\left(x_{i j}\right)_{n \times n}$, 矩阵中元素 $x_{i j}$ 代表元素 $a_{i}$ 影响元素 $a_{j}$ 的程度, 并且 将其对角线元素设为 0 。

(3) 直接影响矩阵的归一化。

(4) 计算综合影响矩阵 T。

（5）计算各影响因素的影响度 R 、被影响度 $D$ 、中心度 $R+D$ 和原因度 $R-D$ 。

（6）绘制因果关系图。

ANP (Analysis Network Process) 是 Saaty ${ }^{[1]}$ 于 1996 年提出的一种适应非独立递阶层次结构的决策 方法。基本步骤如下:

(1) 根据 ANP 原理和评价指针体系, 建立 ANP
评价网络模型。

（2）基于网络模型中各要素间的相互作用, 进 行两两比较。设计调查问卷, 选择有代表性专家, 根 据 Saaty 1-9 级量表, 进行成对比较, 并运用几何平 均数法将专家评分进行整合。

（3）确定未加权超矩阵, 进行一致性检验。

(4) 计算加权超矩阵。

（5）计算极限超矩阵, 确定因素的权重。

\section{3. 结果与分析}

\section{1. 洪涝灾害恢复力影响因素的选取}

在前人研究成果和征求多方面专家意见的基础 上, 从自然维、社会维、经济维、科技维、管理维等 五个维度选取 35 个影响因素。自然维a: 降水因子 $\mathrm{a}_{1}$ 、 水系因子 $\mathrm{a}_{2}$ 、地形因子 $\mathrm{a}_{3}$ 、土地利用类型 $\mathrm{a}_{4}$ 、植被覆 盖率 $\mathrm{a}_{5}$ 、土壤类型 $\mathrm{a}_{6}$; 社会维 $\mathrm{b}$ : 人口密度 $\mathrm{b}_{1}$ 、男女人 口比例 $b_{2}$ 、人口年龄结构 $b_{3}$ 、公众防洪减灾意识 $b_{4}$ 、 医疗卫生救援能力 $b_{5}$ 、社会保障救助能力 $b_{6}$ 、灾后心 理干预能力 $\mathrm{b}_{7}$; 经济维 $\mathrm{c}$ : 区域经济实力 $\mathrm{c}_{1}$ 、个人财力 支撑能力 $\mathrm{c}_{2}$ 、政府财政支持能力 $\mathrm{C}_{3}$ 、区域产业结构 $\mathrm{c}_{4} 、$ 救灾物资储备水平 $\mathrm{C}_{5}$; 科技维 $\mathrm{d}$ : 防灾减灾人才和专 业队伍建设 $\mathrm{d}_{1}$ 、防灾减灾科研及技术应用水平 $\mathrm{d}_{2}$ 、洪 灾监测预警系统的建设水平 $\mathrm{d}_{3}$ 、防洪水利工程的建设 水平 $\mathrm{d}_{4}$ 、生命线工程的建设水平 $\mathrm{d}_{5}$ 、城乡建 (构) 物 的防洪水平 $\mathrm{d}_{6}$ 、救灾应急设备装备水平 $\mathrm{d}_{7}$ 、洪灾信息 数据库的建设水平 $\mathrm{d}_{8}$; 管理维 $\mathrm{e}$ : 相关法律法规的完 善程度 $\mathrm{e}_{1}$ 、洪灾应急预案的完备程度 $\mathrm{e}_{2}$ 、防洪减灾规 划的完备程度 $\mathrm{e}_{3}$ 、防洪减灾指挥体系建设水平 $\mathrm{e}_{4} 、$ 防 洪减灾文化建设水平 $\mathrm{e}_{5}$ 、洪灾信息的管理与服务能力 e6、洪灾风险管理能力建设水平 $\mathrm{e}_{7}$ 、防灾减灾社会动 员能力建设水平 $e_{8}$ 、洪灾保险制度的完善程度 $e_{9}$ 。

\section{2. 基于 DEMATEL-ANP 方法的计算}

通过向该领域专家发放问卷的形式, 整理后确定 各维度及各因素间的直接影响矩阵, 然后计算出各维

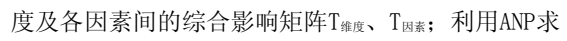
得各影响因素的权重 (表1), 对综合影响矩阵修正之

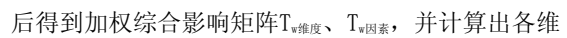
度及各影响因素的影响度 $R$ 、被影响度 $D$ 、原因度 $R$ $-D$ 和中心度 $R+D$ (表 2 )。为了更清哳直观地分析各 影响因素, 以中心度为横坐标, 原因度为纵坐标, 绘 制因果关系图 (图1, 虚线箭头方向仅起指向标记作 用, 实线箭头表示受影响方向)。 
Risk Analysis and Crisis Response in Big Data Era (RAC-16)

表1. 基于ANP的影响因素的权重

\begin{tabular}{|c|c|c|c|c|c|}
\hline 维度 & 指标 & 权重 & 维度 & 指标 & 权重 \\
\hline \multirow{6}{*}{$\begin{array}{l}\text { 自然维 } a \\
(0.268)\end{array}$} & $a_{1}$ & 0.034 & \multirow{8}{*}{$\begin{array}{c}\text { 科技维 } d \\
(0.155)\end{array}$} & $d_{1}$ & 0.049 \\
\hline & $a_{2}$ & 0.041 & & $d_{2}$ & 0.017 \\
\hline & $a_{3}$ & 0.073 & & $d_{3}$ & 0.001 \\
\hline & $a_{4}$ & 0.078 & & $d_{4}$ & 0.045 \\
\hline & $a_{5}$ & 0.012 & & $d_{5}$ & 0.032 \\
\hline & $a_{6}$ & 0.030 & & $d_{6}$ & 0.009 \\
\hline \multirow{7}{*}{$\begin{array}{l}\text { 社会维 } b \\
(0.145)\end{array}$} & $b_{1}$ & 0.107 & & $d_{7}$ & 0.001 \\
\hline & $b_{2}$ & 0.015 & & $d_{8}$ & 0.001 \\
\hline & $b_{3}$ & 0.017 & \multirow{10}{*}{$\begin{array}{c}\text { 管理维 } e \\
(0.107)\end{array}$} & $e_{1}$ & 0.044 \\
\hline & $b_{4}$ & 0.001 & & $e_{2}$ & 0.001 \\
\hline & $b_{5}$ & 0.002 & & $e_{3}$ & 0.056 \\
\hline & $b_{6}$ & 0.002 & & $e_{4}$ & 0.001 \\
\hline & $b_{7}$ & 0.001 & & $e_{5}$ & 0.001 \\
\hline \multirow{5}{*}{$\begin{array}{l}\text { 经济维 } c \\
(0.325)\end{array}$} & $c_{1}$ & 0.086 & & $e_{6}$ & 0.001 \\
\hline & $c_{2}$ & 0.039 & & $e_{7}$ & 0.001 \\
\hline & $c_{3}$ & 0.155 & & $e_{8}$ & 0.001 \\
\hline & $c_{4}$ & 0.044 & & $e_{9}$ & 0.001 \\
\hline & $c_{5}$ & 0.001 & & & \\
\hline
\end{tabular}

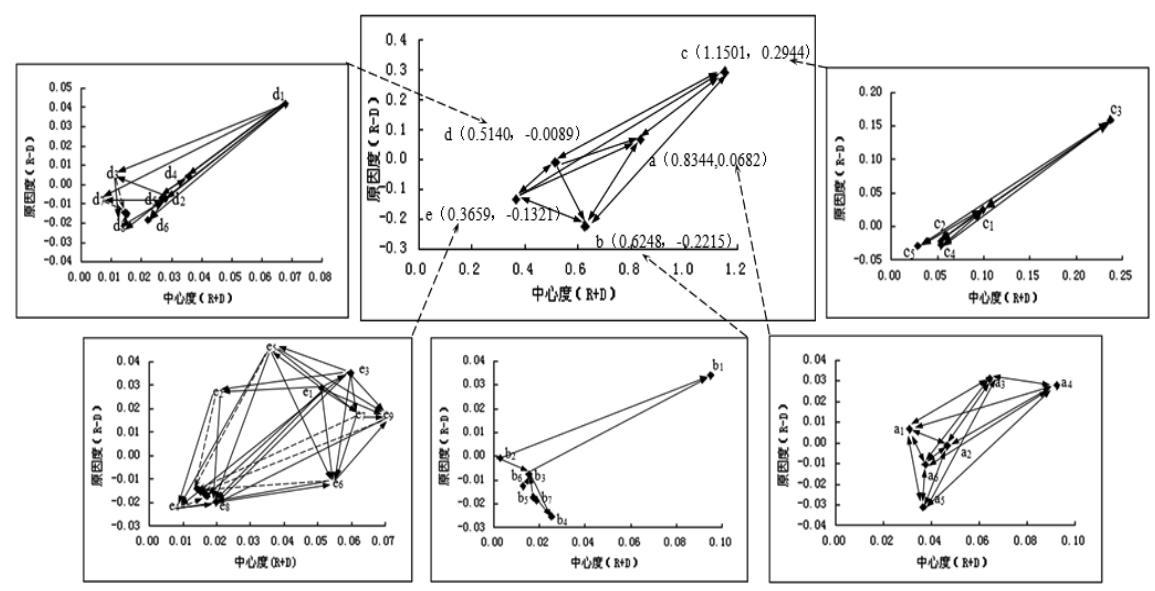

图1. 影响因素的因果图 
Risk Analysis and Crisis Response in Big Data Era (RAC-16)

表2. 因素间的综合关系

\begin{tabular}{|c|c|c|c|c|}
\hline 因素 & 影响度 & 被影响度 & 中心度 & 原因度 \\
\hline$a_{1}$ & 0.019 & 0.012 & 0.031 & 0.007 \\
\hline $\mathrm{a}_{2}$ & 0.023 & 0.024 & 0.046 & -0.001 \\
\hline$a_{3}$ & 0.048 & 0.017 & 0.064 & 0.031 \\
\hline $\mathrm{a}_{4}$ & 0.060 & 0.032 & 0.093 & 0.028 \\
\hline $\mathrm{a}_{5}$ & 0.003 & 0.034 & 0.037 & -0.031 \\
\hline $\mathrm{a}_{6}$ & 0.014 & 0.024 & 0.038 & -0.011 \\
\hline $\mathrm{b}_{1}$ & 0.065 & 0.031 & 0.095 & 0.034 \\
\hline $\mathrm{b}_{2}$ & 0.001 & 0.002 & 0.003 & -0.001 \\
\hline$b_{3}$ & 0.004 & 0.012 & 0.015 & -0.008 \\
\hline $\mathrm{b}_{4}$ & 0 & 0.025 & 0.025 & -0.025 \\
\hline $\mathrm{b}_{5}$ & 0.000 & 0.019 & 0.019 & -0.019 \\
\hline$b_{6}$ & 0.000 & 0.013 & 0.013 & -0.013 \\
\hline $\mathrm{b}_{7}$ & 0.000 & 0.017 & 0.017 & -0.017 \\
\hline $\mathrm{c}_{1}$ & 0.062 & 0.037 & 0.099 & 0.026 \\
\hline $\mathrm{c}_{2}$ & 0.013 & 0.041 & 0.054 & -0.028 \\
\hline$c_{3}$ & 0.198 & 0.039 & 0.237 & 0.159 \\
\hline $\mathrm{c}_{4}$ & 0.015 & 0.038 & 0.053 & -0.023 \\
\hline $\mathrm{c}_{5}$ & 0.000 & 0.029 & 0.029 & -0.029 \\
\hline $\mathrm{d}_{1}$ & 0.055 & 0.013 & 0.068 & 0.042 \\
\hline $\mathrm{d}_{2}$ & 0.010 & 0.018 & 0.028 & -0.007 \\
\hline$d_{3}$ & 0.000 & 0.015 & 0.015 & -0.015 \\
\hline $\mathrm{d}_{4}$ & 0.020 & 0.016 & 0.036 & 0.004 \\
\hline $\mathrm{d}_{5}$ & 0.010 & 0.017 & 0.027 & -0.007 \\
\hline $\mathrm{d}_{6}$ & 0.002 & 0.020 & 0.022 & -0.018 \\
\hline $\mathrm{d}_{7}$ & 0.000 & 0.015 & 0.015 & -0.015 \\
\hline $\mathrm{d}_{8}$ & 0.000 & 0.015 & 0.015 & -0.015 \\
\hline $\mathrm{e}_{1}$ & 0.040 & 0.011 & 0.051 & 0.029 \\
\hline $\mathrm{e}_{2}$ & 0.000 & 0.014 & 0.014 & -0.014 \\
\hline$e_{3}$ & 0.047 & 0.012 & 0.060 & 0.035 \\
\hline$e_{4}$ & 0.000 & 0.017 & 0.017 & -0.017 \\
\hline $\mathrm{e}_{5}$ & 0.000 & 0.014 & 0.014 & -0.014 \\
\hline $\mathrm{e}_{6}$ & 0.000 & 0.016 & 0.016 & -0.016 \\
\hline $\mathrm{e}_{7}$ & 0.000 & 0.015 & 0.015 & -0.015 \\
\hline$e_{8}$ & 0.000 & 0.020 & 0.0208 & -0.020 \\
\hline $\mathrm{e}_{9}$ & 0.000 & 0.017 & 0.017 & -0.017 \\
\hline
\end{tabular}

\section{3. 因素间影响关系的识别}

3.3.1. 指标权重的分析

根据 ANP 得到的权重, 表 1 显示权重最大的分别 为政府的财政支持能力、人口密度、区域经济实力, 权重之和达 0.35 , 主要因为政府是区域防灾减灾的 主体, 其在防灾减灾领域的财政投入对防灾减灾能力 建设的产生最直接有效的影响; 而人口密度以及区域 经济实力对灾情起到放大或者缩小的效果, 宏观上对 社会经济系统的洪灾恢复的影响最广泛。

\subsection{2. 因素间影响关系的识别}

从表2中的影响度上看, 政府财政支持能力、经 济实力、土地利用类型对其他因素的影响显著, 其中 政府财政支持能力最为重要, 其直接关系到区域防灾 减灾能力的建设水平, 影响工程建设、人才及专业队 伍的建设、科学研究及应用、物资储备、洪灾管理等; 其次是区域的经济实力, 除了决定政府财政支持能力 和个人财力支撑能力, 也很大程度上影响着区域的土 地利用类型, 人口密度; 而土地利用类型也对政府财 政支持能力、个人财力支撑能力、经济实力、产业结 构、植被覆盖率等有相当影响。从被影响度上看, 个 人财力支撑能力、政府财政支持能力、产业结构最容 易受其他因素影响, 需要引起关注。从中心度上看, 表6、图1表明: 区域洪害恢复力影响因素中, 政府财 政支持能力、经济实力、土地利用类型与其他因素关 系最为密切, 在所有因素中处于核心的位置。并且可 以看出中心度最高的前三个因素也是影响度最高的 前三个, 说明对于这三个因素, 其影响度对于中心度 的贡献显著。

图 1、表 2 表明, 原因因素共有 9 个, 按原因度 的降序排列分别为政府财政支持能力、防灾减灾人才 及专业队伍建设水平、防洪减灾规划的完备程度、人 口密度、地形因子、相关法律法规的完善程度、土地 利用类型、经济实力、防洪水利工程的建设水平。可 以看出政府财政支撑能力的原因度依旧最大, 再次说 明其在区域洪灾恢复力影响因素中的关键位置; 其次 是防灾减灾人才及专业队伍的建设水平, 其对防洪减 灾科学研究与应用、工程建设、技术支持、专业救援、 洪灾管理等方面都产生重要影响; 而防洪减灾规划的 完备程度关系到未来区域防洪减灾建设的科学性、可 行性、全面性及针对性, 涉及区域洪灾恢复力的五个 维度, 例如科学规划土地利用类型、引导人口及产业 的合理分布、加强洪灾的监测预警系统的建设、完善 洪灾抢险救援指挥体系、建立健全洪灾保险制度等; 人口密度较大程度上决定着人类社会经济活动的强 度, 在深刻影响社会经济系统的同时, 也在改造着区 
Risk Analysis and Crisis Response in Big Data Era (RAC-16)

域的自然环境。地形因子很大程度上决定着孕灾环境 的稳定性，进而影响着人口分布及社会经济活动范 围; 相关法律法规则是洪灾管理的基础; 土地利用类 型也对人口分布、区域经济实力、政府财政支持能力、 区域产业结构等有很大影响; 经济实力不仅是经济维 中的根本动力, 也对其他维度中的因素产生影响; 防 洪水利工程是对孕灾环境的直接改造, 改善了人类社 会经济活动的地理空间。

\subsection{3. 基于重要性及关联性的影响因素分析}

通过影响因素的权重、影响度、被影响度、中心 度、原因度分析发现，政府的财政支持能力、人口密 度、经济实力、土地利用类型等影响因素的重要性与 关联性都很高, 说明了它们在区域洪涝灾害恢复力影 响因素指标体系中的核心位置, 但影响因素的重要性 和关联性并不一定同步, 例如植被覆盖率的权重占比 排序为 19 名, 中心度排序为 12 名, 因此在关注权重占 比高的因素同时, 也需要改善那些关联度高的因素, 因为它们在区域洪涝灾害恢复力影响因素指标体系 中, 起到某种网络节点的作用, 改善它们可以影响其 他受影响的因素, 也需要考虑它们自身受到的影响所 带来的改善难易程度问题。

\section{4. 结论}

基于DEMATEL-ANP的分析法, 识别区分不同类 型的因素以及不同因素需要改善的紧迫性和难易度, 为复杂系统的决策管理提供较为科学合理的决策支 持。综合分析得出政府财政支持能力、防灾减灾人才 及专业队伍建设水平、防洪减灾规划的完备程度、人 口密度、地形因子、相关法律法规的完善程度、土地 利用类型、经济实力、防洪水利工程的建设水平等 9 个因素是主要的影响因素。优化这些因素可以提高区 域洪涝灾害恢复力的水平。

\section{5. 参考文献}

[1] 葛怡,史培军,徐伟,等.恢复力研究的新进展与评 述.灾害学,2010,25(3):120-124.

[2] 刘婧,史培军,葛怡,等.灾害恢复力研究进展综述. 地球科学进展,2006,21(2):212-218

[3] UN/ ISDR. Living with risk: a global review of disaster reduction initiatives. Preliminary version prepared as an interagency effort coordinated by the ISDR Secretariat Geneva, Switzerland ,2002

[4] Pelling M. The Vulnerability of Cities: Natural Disasters and Social Resilience. London, UK: Earthscan, 2003.

[5] Riyanti D, Cameron H, Frank T, et al .Pathways for adaptive and integrated disaster resilience. Natural azards, 2013,69(3):2105-2135.
[6] 葛怡,史培军,周忻.水灾恢复力评估研究: 以湖南 省长沙市为例. 北京师范大学学报 (自然科学 版),2011,47(2):197-200.

[7] 张灵,陈晓宏, 千怀遂. 北江下游防洪保护区恢复 力诊断.水利学报, 2011,42(9):1129-1134.

[8] Cheng X F, Sun H H, Zhang Y, et al. Flood Disaster Risk Assessment and Spatial Distribution Characteristics along the Yangtze River in Anhui Province. Journal of Risk Analysis and Crisis Response, 2014,4(4):238-242.

[9] Chan S L,Wey W M, Chang P H.Establishing Disaster Resilience Indicators for Tan-sui Rive Basin in Taiwan. Social Indicators Research, 2014,115(1):387-418.

[10] Sadiq A A, Douglas S N. Flood disaster management policy:an analysis of the United States Community Ratings System. Journal of Natural Resources Policy Research,2015,7(1):6-22

[11] Saaty T L.Decision making with dependence and feedback. Pittsburgh: RWS Publication, 1996:26-67. 